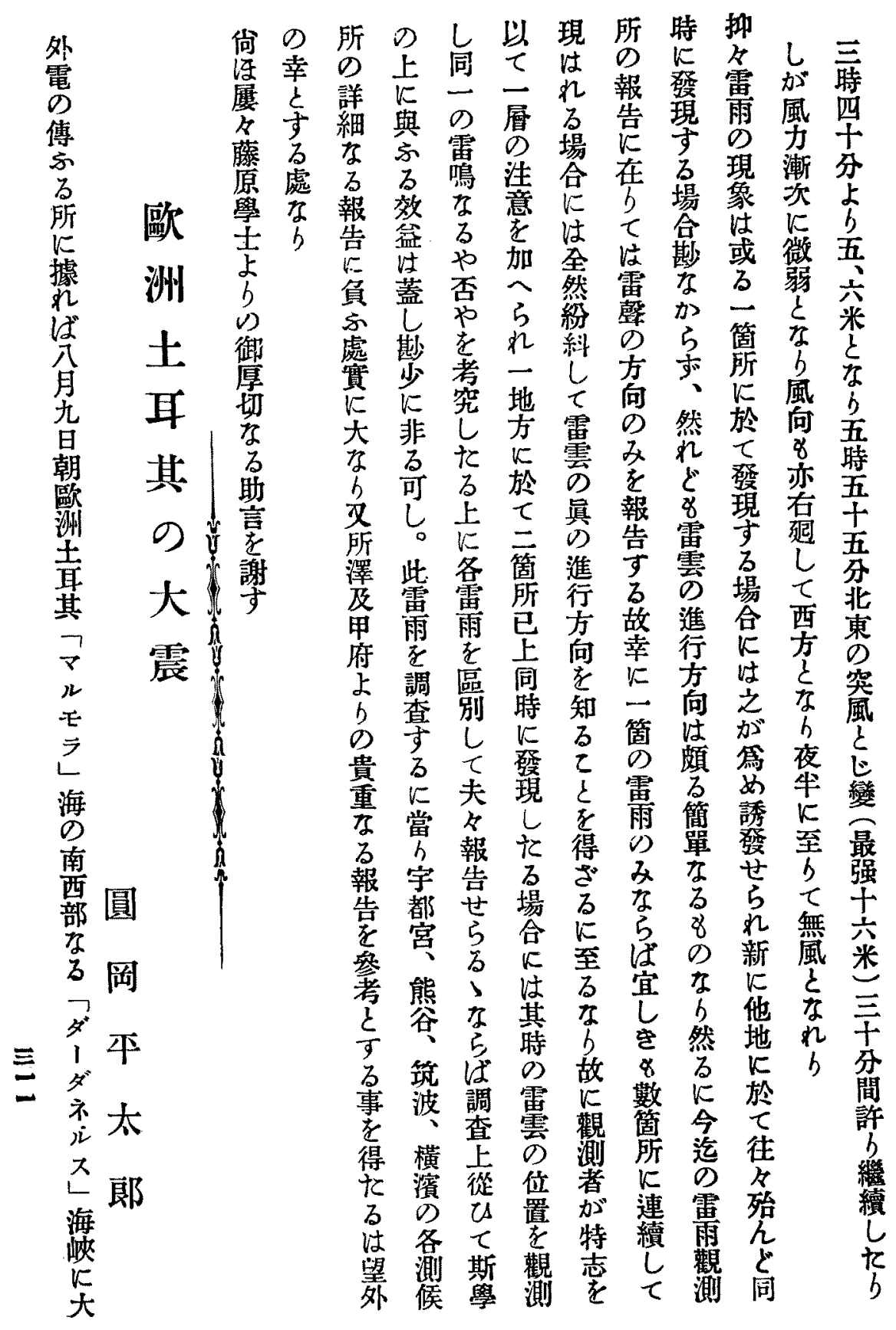


細離る二間而波國名を所百し地 はに心分はし斯南に失依中名避震

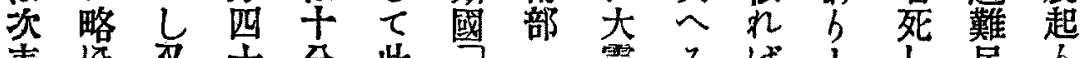

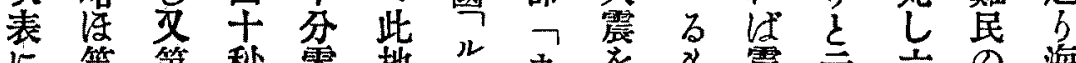
に等第秒零地少力を 8 震云六の海

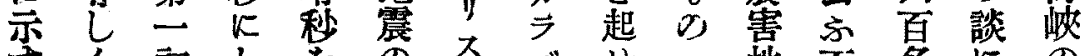

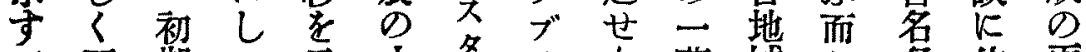
が而期飞示天夕多萬域し負依霜

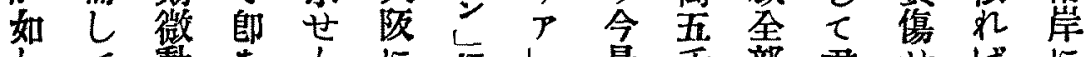
して動 ち

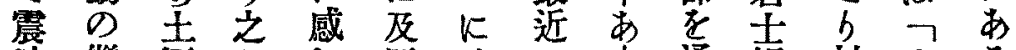
波繼耷尔同、の通坦村木る

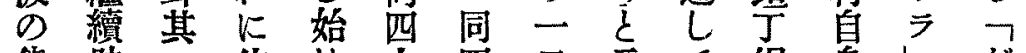

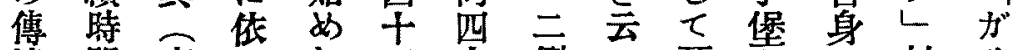
薘間東て て四千例方死走村 8

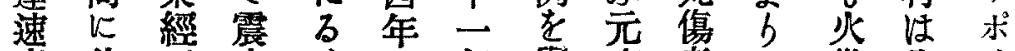
度依至央注二年擧來者口荻全”

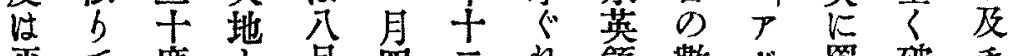

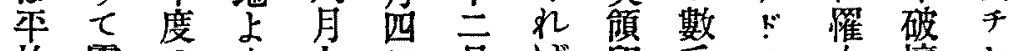
均震の方光星ば角妓门壤ヤ 每央 特大王去明度三 秒地刻陌午聂治邀面, 他八》

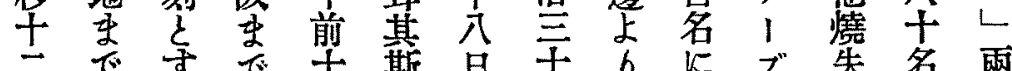

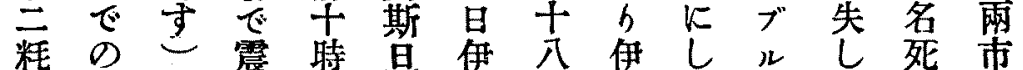
五距の波四宫國年太飞

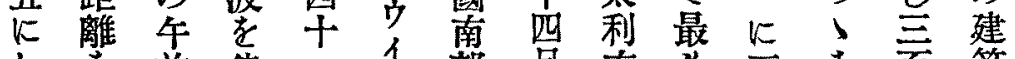
し 煎傳 $\bar{x}$ 部月南8 至

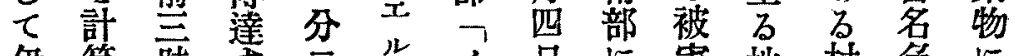

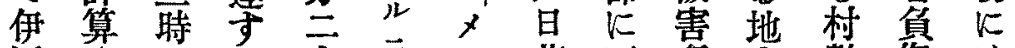
國导严主

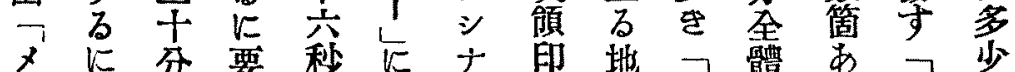

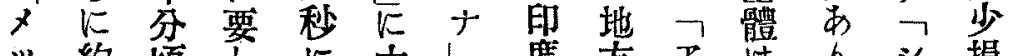

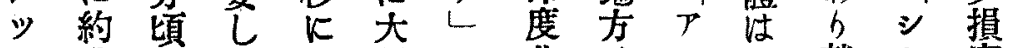

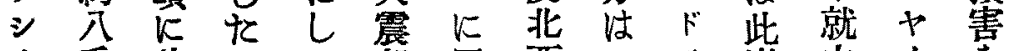

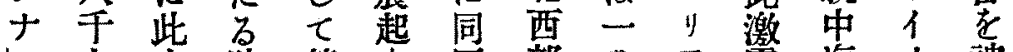

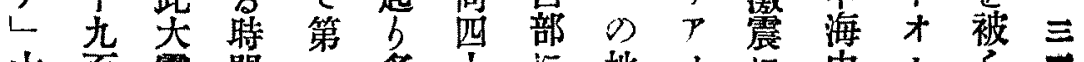

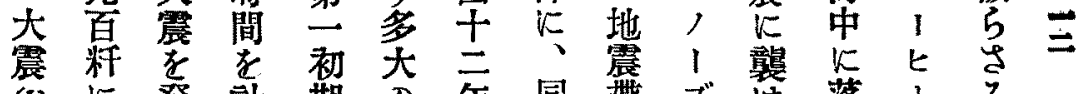

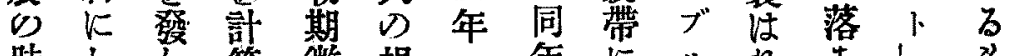
特しし算微損一年にルれ占し8

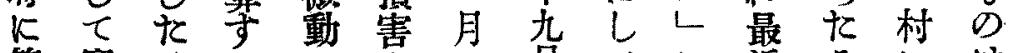

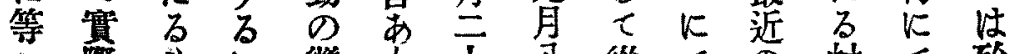
乙蔡

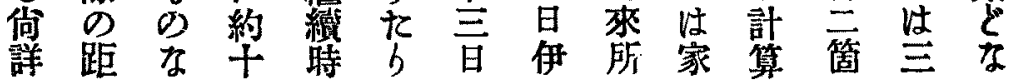




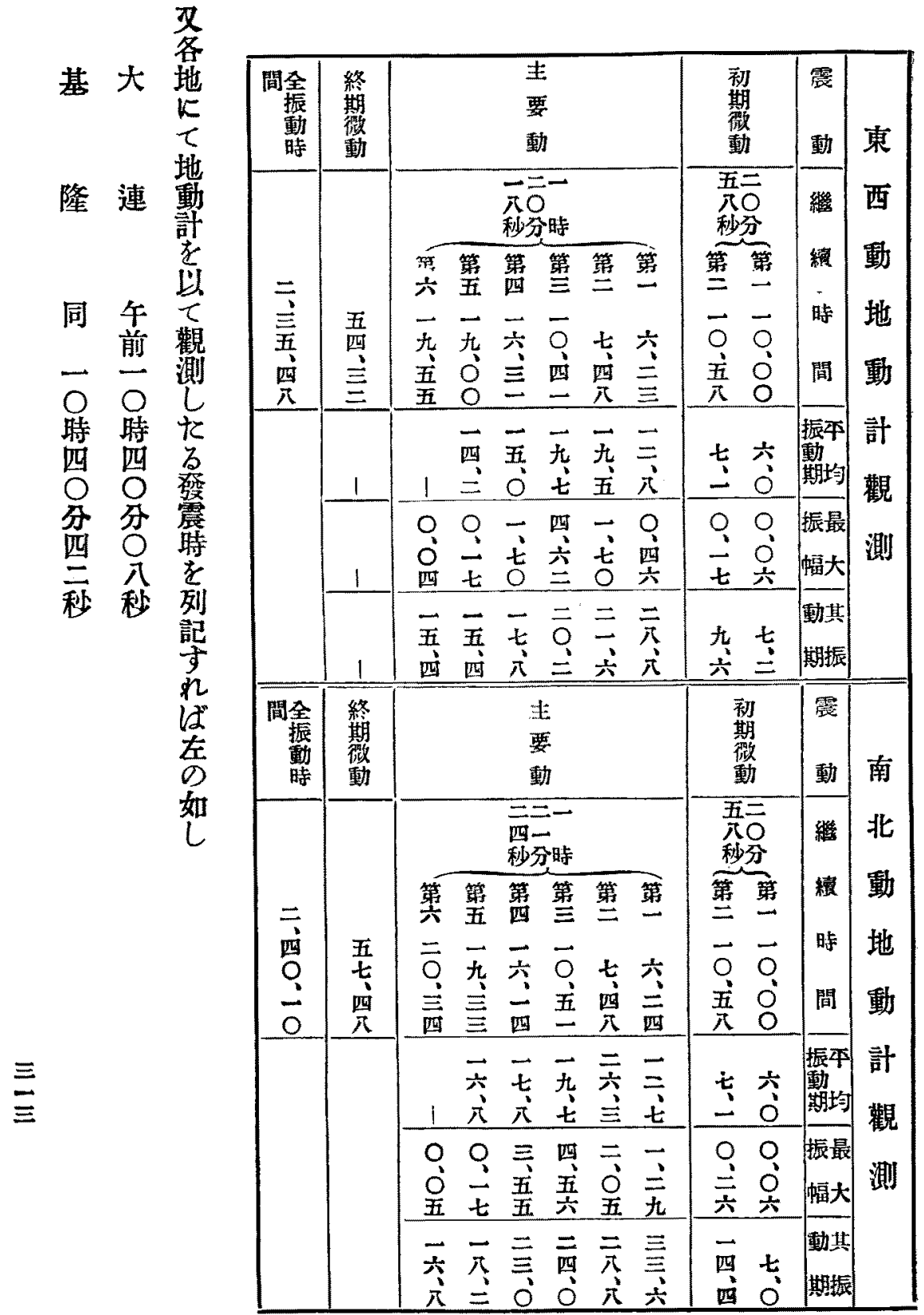




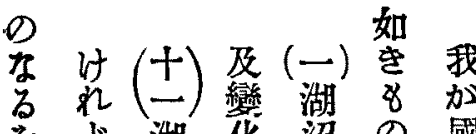

ぞ湖花沼の國

感 方沼のでた

E余 $D($ (七) 種あ於

た性生水類る讨

三物 $D$ 西

三 振( 云) 湖

の (声) 動 湖 沼

沿永準学究

色口形标

調 異 狀

查 (声) 筒 ） 至

七湖（八）湖

氣沼 湖 沼

象 水 $D$

分 $の$ 成

影布含因

量物（四）

偉

大

な

惹

知

万候 型

湖

沼

研閶辟

究 係

氣望五)

象湖 沼

沼

深

排 淺

水

点 (六)

せ 關

曉

の

星

管

子

要

有
マ 東大仁
$=$

F京阫川

同同同同同

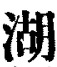

沼

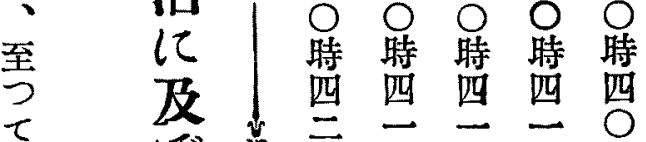

位芬分分分分

5

棬

で

あ 鵜

が

研

究 沼

事

項

会 彥 


\section{NOTO JE LA TERTREMO EN DARDANELA MARKOLO.}

DE

\section{H. MARUOKA.}

Laŭ jurnaloj okazis, matenon de la ga aŭgusto, en la cirkaŭajo de dardanela markolo tre forta tertremo, kiu detruis grandan nombron da domoj kaj ế kaŭzis al centoj da popoloj la perdon de vivo.

$\hat{C}_{i}$ tie en Osaka, la sismografo tre klare registris la tremadojn. La unua antaŭtremetado komencis je $10^{\mathrm{h}} 4 \mathrm{I}^{\mathrm{m}} 26^{\mathrm{g}} \mathrm{kaj}$ daŭris 10 minutojn ; tio donas por la distanco gis la epicentro 8900 k.m., kiu bone respondas al la efektiva. Ċar la tremado bezonas cirkaŭ Iom $40 \mathrm{~s}$ por sin propagi gis ni, en dardanela markolo $\mathrm{g} i$ devas esti okazinta je çirkaŭ $3 \mathrm{~h}$ 3om matene (laŭ la meztempo de $30 a$ grada meridiano, oriente de Greenwich).

La observitajoj de Osaka estas donitaj en jena tabelo:

E.W tremado

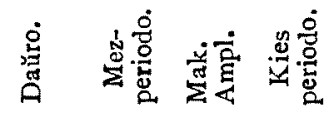

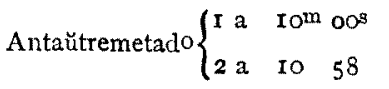

$\begin{array}{lll}6.0 & 0.06 \quad 7.2\end{array}$

$\begin{array}{lll}7.1 & 0.17 & 9.6\end{array}$

Ceftremado $\left\{\begin{array}{rrrrrr}\text { I a } & 6 & 23 & 12.8 & 0.46 & 28.8 \\ 2 \text { a } & 7 & 48 & 19.5 & 1.70 & 21.6 \\ 3 \text { a } & 10 & 41 & 19.7 & 4.62 & 20.2 \\ 4 \text { a } & \text { 16 } & 31 & 15.0 & 1.70 & 17.8 \\ 5 \text { a } & 19 & 00 & 14.2 & 0.17 & 15.4 \\ 6 \text { a } & \text { I9 } & 55 & - & 0.04 & 1.54\end{array}\right.$

Fintremetado

Tuta daŭro
$54 \quad 32$

$2^{\mathrm{h}} \quad 35^{\mathrm{m}} 48^{\mathrm{s}}$
N-S tremado

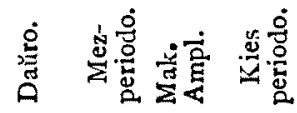

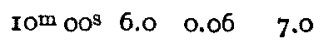$$
\begin{array}{llll}
10.58 & 7.1 & 0.26 & 14.4
\end{array}
$$$$
\begin{array}{llll}
6.24 & 12.7 & 1.29 & .336
\end{array}
$$$$
\begin{array}{llll}
7.48 & 2.63 & 2.05 & 2.88
\end{array}
$$$$
\begin{array}{llll}
10.51 \quad 19.7 & 4.56 \quad 2.40
\end{array}
$$$$
\begin{array}{llll}
\text { I6.14 } & \text { I7.8 } & 3.55 & 2.30
\end{array}
$$$$
\begin{array}{llll}
\text { I9.33 } & 16.8 & 0.17 & \text { I. } 82
\end{array}
$$$$
20.34-0.05 \quad 1.68
$$

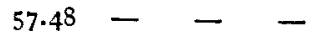

$2^{\mathrm{b}} 4 \mathrm{O}^{\mathrm{m}} \mathrm{IO}^{\mathrm{s}}$ 